\title{
$\mathrm{MIMO}$ 레이다 환경에서 Polar Format Processing 기반 이동표적 이미징
}

\section{Polar-Format-Processing-Based Moving Target Imaging in MIMO Radar Environment}

\author{
최 상 현·양 훈 기 \\ Sang-Hyun Choi $\cdot$ Hoon-Gee Yang \\ 요 약
}

본 논문은 여러 송수신 레이다들이 지상에 고정된 $\mathrm{MIMO}$ (multiple input multiple output) 레이다 환경에서 이동표적을 이미징할 수 있는 알고리즘을 제시한다. 제시된 알고리즘은 평면파 근사를 사용한 polar format processing에 기반한 것으 로 수신 레이다 간 이격이 큰 경우에도 복수의 송신 레이다를 사용해서 앨리어싱(aliasing) 현상이 배제된 이동표적 이미 지를 얻을 수 있음을 보인다. 앨리어싱 현상을 줄이면서 해상도를 높일 수 있는 송신 레이다 배치에 대한 조건을 제시하 며, 또한 각 송신 레이다에 의한 표적 산란 신호를 수신 레이다에서 분리시킬 수 있는 방법을 제시한다. 마지막으로 시뮬 레이션을 통해서 제시된 $\mathrm{MIMO}$ 레이다 시스템의 성능을 검증한다.

Abstract

This study presents an imaging algorithm that can provide an image of a moving target in a multiple-input - multiple-output radar environment where multiple transmitting and receiving radars are fixed on the ground. The proposed algorithm, which is based on polar format processing using plane wave approximation, is shown to provide an unaliased image by using multiple transmitting radars even when the distances between the receiving radars are relatively large. We derive the conditions necessary to deploy the transmitting radars by which the resolution of the reconstructed image can be improved, while simultaneously reducing aliasing artifacts. Moreover, we offer a means of separating out each transmitting radar target echo. Finally, the performance of the proposed system is verified through a simulation.

Key words: Radar, Polar, SAR, MIMO, GMTI

I. 서 론

스텔스, 무인기 기술이 발전함에 따라 저피탐 이동 표
적에 대한 탐지 및 식별에 대한 필요성이 증가하고 있다. 공중 이동 표적을 탐지하기 위해서 PBR(passive bistatic radar) 기법, ISAR(inverse synthetic aperture radar) 이미징

「이 연구는 2018년도 정부(미래창조과학부)의 재원으로 한국연구재단의 지원을 받아 수행된 기초 연구 사업입니다(NO. NRF-2017R1A2B4008044, 다채널 DPCA 및 STAP 기반 SAR-GMTI 알고리즘 개발)」

광운대학교 전파공학과(Department of Radio Sciences and Engineering, Kwangwoon University)

· Manuscript received October 11, 2018 ; Revised November 14, 2018 ; Accepted January 14, 2019. (ID No. 20181011-106)

· Corresponding Author: Hoon-Gee Yang (e-mail: hgyang@kw.ac.kr) 
기법 등 다양한 신호처리 기법이 연구되고 있다 $[1],[2]$.

$\mathrm{PBR}$ 은 기존의 방송, 통신, 무선항법 등 송신 신호를 사 용하여 표적을 탐지하는 기술로서 레이다에서 사용하지 않는 VHF, UHF 주파수 대역을 사용하기 때문에 스텔스 표적 탐지에 유리하다 ${ }^{[3]}$.

ISAR는 표적의 회전 또는 이동 운동을 이용해서 aperture 를 합성해서 표적의 이미지를 형성하는 기법으로복원된 이미지의 해상도가 표적의 움직임에 의존적이므로 움직임 에 대한 추정이 필요하다 ${ }^{[2]}$. 모노스태틱(monostatic) ISAR 의 한계점을 극복하기 위해 여러 개 송수신 레이다들을 이격 시켜 배치하는 MIMO ISAR 혹은 멀티스태틱 ISAR 기법과 같은 distributed ISAR 기법이 제안되었다 ${ }^{[4]}$. 그러나 distributed ISAR 기법은 비협조적인 표적의 reference point와 레이다간의 거리를 정확히 알아내어 표적의 radial motion 을 보상하는 autofocus 프로세싱이 여전히 요구되고 있다 ${ }^{[5]}$.

최근에 지상에 다수의 수신기/수신 레이다를 배치하고 바이스태틱 레이다 환경에서 GMTI(ground moving target indicator) 알고리즘을 적용해서 이동 표적을 탐지하는 알 고리즘이 제안되었다 ${ }^{[6]}$. 이 방식은 평면파 근사화(planewave approximation)를 적용해서 수신기의 지상에서의 위 치에 대한 제약을 완화시키면서 SAR 알고리즘을 적용시 킬 수 있었다. 하지만 송신기/송신 레이다와 표적 산란점 까지의 거리를 근사화시켜 바이스태틱 환경을 모노스태 틱 환경으로 변환시킴으로써 표적 이미지의 위치 오차 (dislocation) 및 퍼짐(blurring)이 야기되었다. 본 논문에서 는 송신부와 표적 산란점 간의 거리를 평면파 근사화시 켜 멀티스태틱 레이다 환경에서 표적을 이미징하는 방법 을 제시한다. 특히 수신 레이다들에 대한 위치 제약을 완 화하기 위해서 복수의 송신기를 사용하였으며, 이로 인해 공간 주파수 평면에서 표적 신호가 차지하는 영역의 확 대가 가능하여 위치 오차와 퍼짐을 완화하고, 해상도도 높일 수 있는 $\mathrm{MIMO}$ 레이다 환경에 적용할 수 있는 알고 리즘을 제시한다.

II 절에서는 제안 $\mathrm{MIMO}$ 레이다 환경에서 이동 표적을 이미징하는 방법을 제시하고, 공간 스펙트럼 분석을 통한 다수의 송신기 배치 방안, 그리고 각 송신기가 직교 (orthogonal) 신호를 사용한 MIMO 시스템 구성 외에도 시 간적으로 송신 펄스 송신 시간을 조정해서 거의 $\mathrm{MIMO}$ 를
닮은 환경으로 제안 시스템을 구현할 수 있는 방법을 설 명한다. III절에서는 시뮬레이션을 통해 제안 방법에 의한 표적 이미징 성능을 보이고, IV 절에서 결론을 맺는다.

\section{II. 이미징 알고리즘}

\section{2-1 송수신 시스템 모델링}

그림 1 은 $M$ 개의 송신기와 $N$ 개의 수신기를 이용해서 공중에 존재하는 이동 표적을 탐지 및 이미징하는 이차 원 레이다 시스템을 나타낸다. 참고로 제안 레이다 시스 템은 3 차원으로 확장 가능하며, 수식의 단순화를 위해 2 차원 레이다 환경으로 가정하였다.

$x$ 축은 지상을, $y$ 축은 고도를 나타내며, 표적 영역은 중 심이 $\left(X_{1}, Y_{1}\right)$ 이고, 반지름이 $X_{0}$ 인 원으로 표시되어 있 으며, 표적 영역 내에 이동 표적이 존재한다. $M$ 개의 송 신기 및 $N$ 개의 수신기는 공간 동기(space synchronization) 가 이루어져 있어서 매순간 각각의 송수신기의 송수신빔 은 동일한 표적 영역을 조향하고 있다고 가정하자.

$m$ 번째 송신기는 $\left(x_{T_{m}}, y_{T_{m}}\right) \quad(m=1,2, \ldots, M)$ 에 위 치해 있으며, $m$ 번째 송신기와 표적 중심 $\left(X_{1}, Y_{1}\right)$ 이 이 루는 각도 $\theta_{T_{m}}$ 은 $\theta_{T_{m}}=\arctan \left(\frac{Y_{1}-y_{T_{m}}}{X_{1}-x_{T_{m}}}\right)$ 이 된다. 수 신기들은 $(0,0)$ 을 중심으로 $x$ 축 상에 있으며, $n$ 번째 수 신기는 $\left(u_{n}, 0\right)(n=1,2, \ldots, N)$ 에 위치해 있다. 그러므

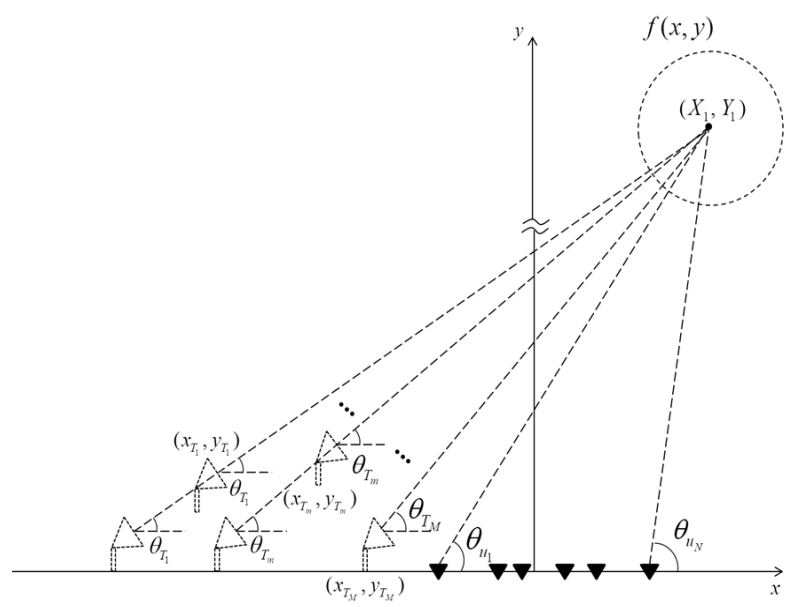

그림 1. 제안 레이다 환경

Fig. 1. Proposed radar system. 
로 $n$ 번째 수신기는 $\theta_{u_{n}}=\arctan \left(\frac{Y_{1}}{X_{1}-u_{n}}\right)$ 로 정해지 는 $\theta_{u_{n}}$ 방향을 조향한다. 여기서 $N$ 개의 수신기는 디지털 빔포밍(beamforming)에 의해 수신 빔을 조향하는 것이 아 니라, 각각의 수신기들이 독립적으로 $\left(X_{1}, Y_{1}\right)$ 방향으로 빔포밍을 한 것이다. 그러므로 배열 신호처리에서 요구되 는 수신기 간 동일한 간격 조건은 적용되지 않는다.

다음은 $m$ 번째 송신기의 송신 펄스가 방사되어 표적 영역에서 산란된 후 $n$ 번째 수신기에 도달했을 때 수신신호 및 표적 영역의 반사계수 간의 관계를 유도한 과정이다.

$\left(x_{T_{m}}, y_{T_{m}}\right)$ 에 위치한 송신기에서 송신한 펄스가 $\left(X_{1}+x\right.$, $\left.Y_{1}+y\right)$ 에 위치한 산란점에 반사되어 수신기로 도달할 때, $n$ 번째 수신기에 수신된 수신신호 $s_{T_{m}}\left(t, u_{n}\right)$ 은 다음 과 같이 표현된다.

$$
s_{T_{m}}\left(t, u_{n}\right)=\iint f(x, y) p\left(t-\frac{r(x, y)}{c}\right) d x d y
$$

여기서 $c$ 는 전파속도, $p(t)$ 는 송신신호, $f(x, y)$ 는 송신 펄스가 표적에서 반사되는 순간의 표적 반사계수, $r(x, y)$ 는 송신기-표적-수신기에 해당하는 경로 거리를 나타내 며, 다음과 같이 표현된다.

$$
r(x, y)=r_{T_{m}}(x, y)+r_{u_{n}}(x, y)
$$

여기서 $r_{T_{m}}(x, y)$ 는 송신기와 산란점 간의 거리, $r_{u_{n}}(x, y)$ 는 산란점과 수신기 간의 거리를 나타낸다. 표적 산란점과 송수신단 간의 거리가 충분히 크다고 가정하면 $r_{T_{m}}(x, y)$ 와 $r_{u_{n}}(x, y)$ 는 평면파 근사화를 적용하여 각각 다음과 같이 근사화 시킬 수 있다.

$$
\begin{aligned}
& r_{T_{m}}(x, y)=\sqrt{\left(\left(X_{1}+x\right)-x_{T_{m}}\right)^{2}+\left(\left(Y_{1}+y\right)-y_{T_{m}}\right)^{2}} \\
& \simeq \sqrt{\left(X_{1}-x_{T_{m}}\right)^{2}+\left(Y_{1}-y_{T_{m}}\right)^{2}} \\
& \quad+x \cos \theta_{T_{m}}+y \sin \theta_{T_{m}} \\
& r_{u_{n}}(x, y)=\sqrt{\left(\left(X_{1}+x\right)-u_{n}\right)^{2}+\left(Y_{1}+y\right)^{2}} \\
& \simeq \sqrt{\left(X_{1}-u_{n}\right)^{2}+Y_{1}^{2}}+x \cos \theta_{u_{n}}+y \sin \theta_{u_{n}}
\end{aligned}
$$

참고문헌 [6]에서는 $r_{T_{m}}(x, y)$ 를 $\sqrt{\left(X_{1}-x_{T_{m}}\right)^{2}+\left(Y_{1}-y_{T_{m}}\right)^{2}}$ 로 근사화시켜 모노스태틱 환경으로 변환시켰었다. 식 (3) 및 식 (4)를 이용해서 $r(x, y)$ 를 얻은 후 식 (1)에 대입하면 $s_{T_{m}}\left(t, u_{n}\right)$ 를 계산할 수 있다. $s_{T_{m}}\left(t, u_{n}\right)$ 의 주파수 도메 인 함수를 $S_{T_{m}}\left(\omega, u_{n}\right)$ 이라고 하면 이 신호는 다음과 같 이 표현된다.

$$
\begin{aligned}
& S_{T_{m}}\left(\omega, u_{n}\right) \simeq \\
& \quad P(\omega) \exp \left(-j k\left(\sqrt{\left(X_{1}-x_{T_{m}}\right)^{2}+\left(Y_{1}-y_{T_{m}}\right)^{2}}\right)\right) \\
& \quad \times \exp \left(-j k\left(\sqrt{\left(X_{1}-u_{n}\right)^{2}+Y_{1}^{2}}\right)\right) \\
& \quad \times F\left(k\left(\cos \theta_{u_{n}}+\cos \theta_{T_{m}}\right), k\left(\sin \theta_{u_{n}}+\sin \theta_{T_{m}}\right)\right)
\end{aligned}
$$

여기서 $P(\omega)$ 는 $p(t)$ 의 퓨리에 변환이고, $k$ 는 $k=\frac{\omega}{c}$ 로 정의된 파수(wave number)로서 $p(t)$ 의 주파수 대역폭에 따라 $k$ 의 범위도 정해진다. $F(\cdot, \cdot)$ 는 $f(x, y)$ 의 $x$ 와 $y$ 에 관한 2차원 공간 스펙트럼 함수를 나타낸다. $s_{T_{m}}\left(t, u_{n}\right)$ 이 정합필터 $P^{*}(\omega)$ 를 통과했을 때 식 (5)는 다음과 같이 나타낼 수 있다.

$F\left(k\left(\cos \theta_{u_{n}}+\cos \theta_{T_{m}}\right), k\left(\sin \theta_{u_{n}}+\sin \theta_{T_{m}}\right)\right) \simeq \frac{S_{T_{m}}\left(\omega, u_{n}\right)}{|P(\omega)|^{2}} \times$

$\exp \left(j k\left(\sqrt{\left(X_{1}-u_{n}\right)^{2}+Y_{1}^{2}}+\sqrt{\left(X_{1}-x_{T_{m}}\right)^{2}+\left(Y_{1}-y_{T_{m}}\right)^{2}}\right)\right)$

식 (6)의 좌변 값, 즉 $|P(\omega)|^{2}$ 와 exponential term 안에 존재하는 변수는 주어진 값이므로 $k$ 를 변화시키면서 $F(\cdot, \cdot)$ 를 계산할 수 있다.

\section{2-2 멀티스태틱 공간 스펙트럼}

식 (6)은 하나의 송신 펄스에 대해 하나의 수신기에 수 신된 신호가 공간 스펙트럼 $\left(k_{x}, k_{y}\right)$ (여기서 $k_{x}, k_{y}$ 는 $x$ 와 $y$ 의 공간 주파수를 나타냄)에서 차지하는 영역을 나타낸 다. 즉, 하나의 수신기에 얻어진 샘플 신호는 $\left(k_{x}, k_{y}\right)$ 평면 에서 하나의 line segment 상의 샘플 값( $k$ 에 따라 정해짐)에 대응되며, 수신기가 $N$ 개 존재할 경우 $N$ 개의 line segment 상에 있게 된다. 만약 $M$ 개의 송신기 신호들을 각 수신기 
에서 분리할 수 있다면 표적 신호 샘플들은 $M N$ 개의 line segment 상에 있게 된다. $M N$ 개의 line segment 상의 표적 신호 샘플 값들은 rectangular grid에 인터폴레이션(interpolation)된 후 2차원 역퓨리에 변환을 통해서 표적 영상의 반사계수 $f(x, y)$ 을 얻을 수 있다. Rectangular grid의 간격 $\triangle_{g r i d}$ 는 복원 영상 크기에 의해 결정되며, 퓨리에 변환 (Fourier transform) 이론에 의해 다음 조건을 만족해야 한다.

$$
\Delta_{\text {grid }}=\frac{2 \pi}{2 X_{0}}
$$

인터폴레이션 오차를 최소화하기 위해서는 $\left(k_{x}, k_{y}\right)$ 평 면에서 샘플 값들 간의 거리는 가까울수록 좋고 복원 영 상의 해상도가 좋아지기 위해서는 샘플 값들이 차지하는 범위가 넓을수록 좋다. 위 두 가지 조건을 달성시키기 위 해 송신기들의 배치를 효과적으로 하는 것이 필요하며, 이것은 $\left(k_{x}, k_{y}\right)$ 평면에서 $M N$ 개의 line segment들의 위치 와 관련이 있다. 이해를 돕기 위한 예시로 4 개의 송신기 와 3 개의 수신기가 있고, 수신기간 이격이 큰 $\mathrm{MIMO}$ 레이 다 환경을 가정하자. 이 경우 표적 신호 샘플들은 12 개의 line segment 상에 있게 된다. 각 line segment들의 위치는 대응되는 송수신기 조향 각도 $\theta_{T_{m}}, \theta_{u_{n}}$ 과 관련이 있으며, 정확히는 조향 각도만큼 두 번 회전된 위치에 있게 된다. 그러므로 4 개의 $\theta_{T_{m}}$ 평균값 및 3 개의 $\theta_{u_{n}}$ 의 평균값에 해 당하는 각도만큼 반대 방향으로 line segment들을 회전시 키면 line segment들의 위치는 그림 2 와 같이 만들 수 있다. 그림 2는 송신기들이 이상적으로 배치된 경우의 $\left(k_{x}, k_{y}\right)$ 평면에서 $M N$ 개 즉 12 개의 line segment들을 보여준다. 즉, 첫 번째 송신기에 대응하는 수신 신호 샘플들은 사잇 각이 큰 3 개의 line segment 상에 있으며, 두 line segment 사이에 다른 두 송신기에 의한 line segment들이 균등하게 위치하도록 하였다. 이것은 한 개의 송신기와 12 개의 수 신기가 있는 경우, 표적 신호 샘플들의 line segment 분포 를 닮게 된다. 그림 2에서 수직 방향의 샘플 간격은 $k$ 의 해상도에 따라 정해지며, 수평 방향의 샘플 간격은 송수 신기 배치에 의해 결정된다. 이상적인 송신기 배치는 다 음 과정을 통해서 유도할 수 있다.

$n$ 번째 수신기와 $m$ 번째 송신기에 의해 얻어지는 line segment의 위치 $\left(k\left(\cos \theta_{u_{n}}+\cos \theta_{T_{m}}\right), k\left(\sin \theta_{u_{n}}+\sin \theta_{T_{m}}\right)\right)$

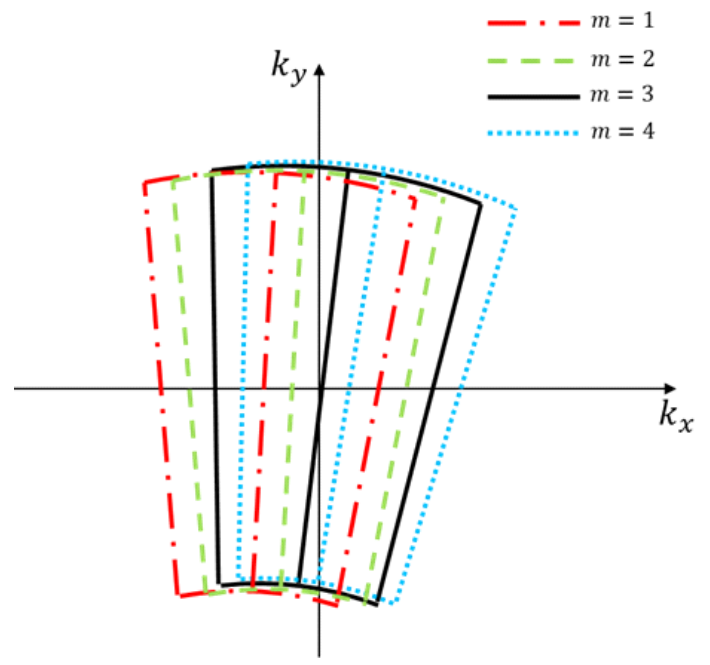

그림 2. 송수신기가 이상적으로 배치된 경우

Fig. 2. Ideal deployment of transmitters and receivers.

와 $n$ 번째 수신기 $m+1$ 번째 송신기에 의해 얻어지는 line segment의 위치 $\left(k\left(\cos \theta_{u_{n}}+\cos \theta_{T_{m+1}}\right), k\left(\sin \theta_{u_{n}}+\right.\right.$ $\left.\left.\sin \theta_{T_{m+1}}\right)\right)$ 간의 간격이 Nyquist 샘플링 이론을 적용해 보 면 $\triangle_{\text {grid }}$ 보다 같거나 작아야 하며, 이는 다음과 같은 수 식으로 표현될 수 있다.

$$
\begin{aligned}
& k_{c} \sqrt{\left(\cos \theta_{T_{m+1}}-\cos \theta_{T_{m}}\right)^{2}+\left(\sin \theta_{T_{m+1}}-\sin \theta_{T_{m}}\right)^{2}} \\
& \leq \Delta_{\text {grid }}
\end{aligned}
$$

예를 들어 송신기들이 지상 $\left(y_{T_{m+1}}=0\right)$ 에 위치할 경우, 식 (8)을 정리하면 다음 식을 얻을 수 있다.

$$
x_{T_{m+1}} \leq X_{1}-\frac{Y_{1}}{\tan \left(\theta_{T_{m}}+\arccos \left(1-\frac{\pi^{2}}{2 X_{0}^{2} k_{c}^{2}}\right)\right)}
$$

식 (9)는 $\theta_{T_{m}}$ 과 관련있는 $m$ 번째 송신기 위치 $x_{T_{m}}$ 가 주 어진 경우 허용 가능한 $m+1$ 번째 송신기의 위치 $x_{T_{m+1}}$ 에 대한 조건으로 $x_{T_{m+1}}$ 이 조건에 충족하지 못하면 복원 영상에 앨리어싱 현상이 포함될 수 있다.

\section{2-3 시스템 동작 구현}

제시된 레이다 시스템이 성공적으로 동작하기 위해서 
는 각 송신기가 송신한 신호를 수신단에서 분리할 수 있 어야 한다. 이를 위해서는 두 가지 방법 적용이 가능하다. 첫 번째 방법은 송신기들이 서로 직교 특성을 갖는 신호 를 동시에 송신하고, 수신단에서 직교성을 이용해서 각각 을 분리하는 것이다. 즉, 완전한 $\mathrm{MIMO}$ 시스템을 구현하 는 것으로 이 경우에는 직교성이 깨지지 않도록 송신기 들 간에 시간 동기가 필수적이며, 또한 각 송신기에 따른 전파 이동 시간(travel time)의 차이가 거의 없어야 한다. 두 번째 방법(이하 virtual MIMO라고 명명할 것임)은 시 간적으로 송신기별 표적신호들을 분리하는 것이다. 본 논 문에서 제안한 시스템의 경우 송신기군과 수신기군이 분 리되어 있어서 복잡한 직교 신호를 만들어 낼 필요 없이 두 번째 방법 적용이 용이하다. 즉, $m$ 번째 송신기가 $t_{m}=t_{0}+(m-1) T_{0}\left(m: 1, \ldots, M, T_{0}\right.$ :상수 $)$ 순간에 송신하고, 시간 동기가 이루어진 $N$ 개의 수신기들이 구간 $\left[t_{m}+\alpha, t_{m}+\beta\right]$ (여기서 $\alpha, \beta$ 는 각각 표적 영역에 의해 결정되는 최소, 최대 전파 이동시간을 나타냄)에서의 표 적 신호만 수신한다면 각 송신기들에 의한 표적 신호를 분리시킬 수 있다. 여기서 $\beta-\alpha$ 는 $\frac{2 X_{0}}{c}$ 에 해당하는 매 우 작은 값이며, $T_{0}$ 크기를 $\beta-\alpha$ 이상만 하면 된다. 하 지만 송신기들이 시간 다중화(time-division multiplexing) 를 해서 펄스를 송신해도 전체 송신 시간 동안에 이동 표 적은 거의 정지해 있다고 가정할 수 있도록 $T_{0}$ 값이 커져 서는 안 되며, $M$ 도 지나치게 커서는 안 된다.

II 절 시작부터 지금까지는 정지 영상으로 가정할 수 있는 이동 표적 영상을 얻는 과정을 설명하였다. 클러터 성분이 크지 않은 환경에서 제시된 방법은 성공적으로 한 순간의 이동 표적 이미징이 가능하다. 제시된 시스템 (MIMO 및 virtual MIMO)에 DPCA(displaced phase center antenna) 기법이 추가된다면 클러터 성분이 큰 레이다 환 경에서 클러터를 억제하면서 이동 표적을 이미징하는데 적용할 수 있다. Virtual MIMO 시스템을 예로 들어보면 $M$ 개의 송신기들이 펄스 송신을 마치고 PRI(pulse repetition interval)시간이 경과한 후 다시 $M$ 개의 송신기들이 펄스 송신 과정을 반복한다. 이 경우, 수신기들은 두 번의 표적 영역에 대한 영상 획득이 가능하며, 두 영상을 빼줌 으로써 클러터 제거 및 이동 표적영상의 획득이 가능하
다. 즉, $m$ 번째 송신기는 $t_{m}$ 에 첫 번째 펄스를 송신하고, $t_{m}+T_{1}$ ( $T_{1}$ :상수)에 두 번째 펄스를 송신한다. 이때 $T_{1}$ 은 $M T_{0}$ 보다는 충분히 커야 하며, 특히 복원된 두 영상 을 빼주었을 때 정지 클러터만 제거되도록 $T_{1}$ 동안 이동 표적의 위치가 충분히 바뀌어야 한다. 또한 빼서 얻어진 영상에는 정지 클러터는 제거되나, 이동 표적의 경우 서 로 다른 두 순간의 표적 영상이 존재하게 된다. 즉, PRI 및 표적 이동속도가 작은 경우는 영상의 퍼짐을 일으키 고, PRI 및 표적 이동속도가 큰 경우는 한 표적이 두 개 표적처럼 보이게 되는 현상이 발생하며, 이를 보상하기 위해서는 이동 표적의 속도 추정 과정이 필요하나, 이는 또 본 연구의 범위를 벗어난 다른 주제이므로 이는 다루 지 않는다.

\section{III. 시뮬레이션}

본 절에서 시간적으로 송신신호들을 분리시키는 virtual MIMO 레이다에 대해 먼저 시뮬레이션을 하였다. 사 용된 시뮬레이션 파라메타는 표 1 과 같다.

우선 송신기가 하나이고, 수신기들이 20개 있는 멀티스 태틱 레이다 환경을 고려하였다. 여기서 표적 성분의 스 펙트럼 샘플들의 이격이 $\triangle_{g r i d}$ 보다 작도록 수신기 간의 거리를 가깝게 하였다. 그림 3(a)는 클러터가 없는 환경에 서 하나의 송신 펄스를 사용했을 때 얻어진 이동 표적 이 미지이다. 그림 3(b)는 이동 표적과 정지 클러터가 함께 존재하는 경우 얻어진 이미지로서 이동 표적이 보이지 않도록 정지 클러터 성분을 크게 하였다. 그림 4 는 두 번

표 1. 시뮬레이션 파라메타

Table 1. Simulation parameters.

\begin{tabular}{|c|c|}
\hline Parameter & Value \\
\hline Carrier frequency $f_{c}$ & $3 \mathrm{GHz}$ \\
\hline PRI & $5 \mathrm{msec}$ \\
\hline Target area $X_{0}$ & $100 \mathrm{~m}$ \\
\hline The number of moving targets & 4 \\
\hline Velocity of moving targets & $1,020 \mathrm{~m} / \mathrm{sec}$ \\
\hline$(M, N)$ & $(1,20),(1,5),(2,5),(4,5)$ \\
\hline Location of $\left(X_{1}, Y_{1}\right)$ & $(300 \mathrm{~m}, 12,000 \mathrm{~m})$ \\
\hline
\end{tabular}




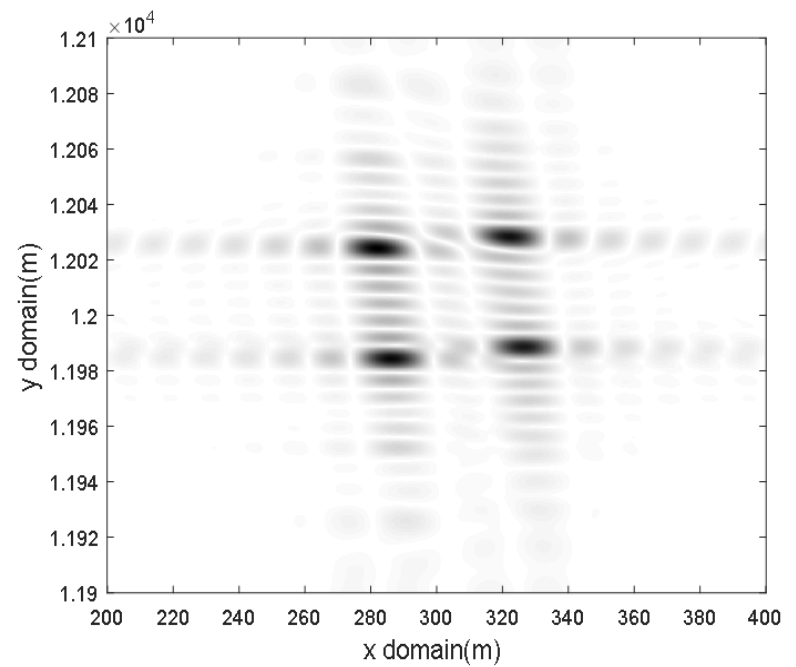

(a) 이동 표적만 존재하는 경우

(a) Case of only moving targets

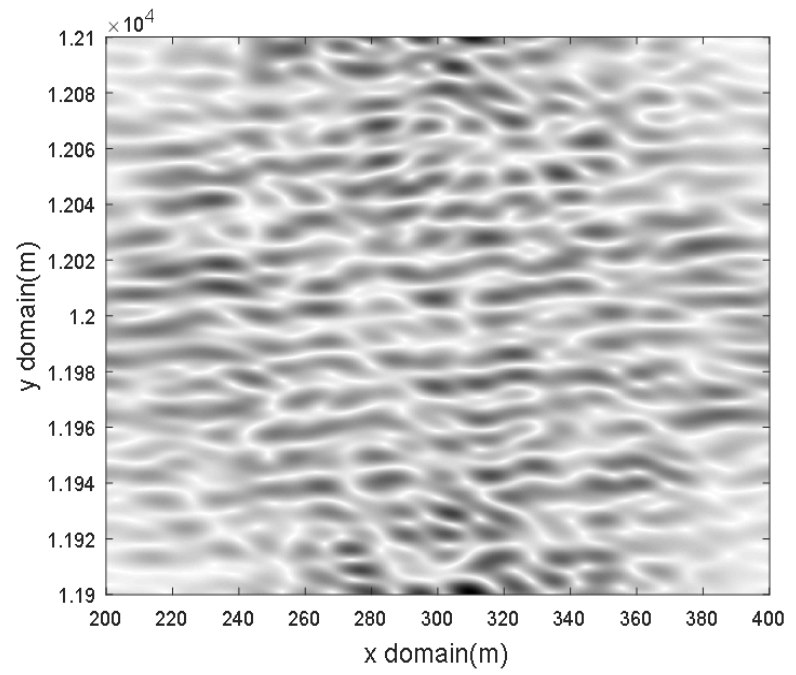

(b) 이동 표적과 정지 클러터가 혼재한 경우

(b) Case of moving targets plus clutter

그림 3. 하나의 송신 펄스로부터 얻은 표적 영역 이미지 Fig. 3. Reconstructed image using single transmit pulse.

의 송신 펄스를 사용해서 얻어진 두 영상을 빼서 이동 표적 이미지만 얻은 경우이다. 실제 이동 표적 이미지는 4 개의 산란점으로 구성되어 있었으나, 두 순간의 이미지가 더해 져서 이동 표적이 8 개의 산란점으로 구성된 것처럼 보인다.

다음은 수신기가 5 개 있고, 여기에 송신기가 각각 1 개 2 개인 경우에 대해서 시뮬레이션하였다. 이때, 표적 성

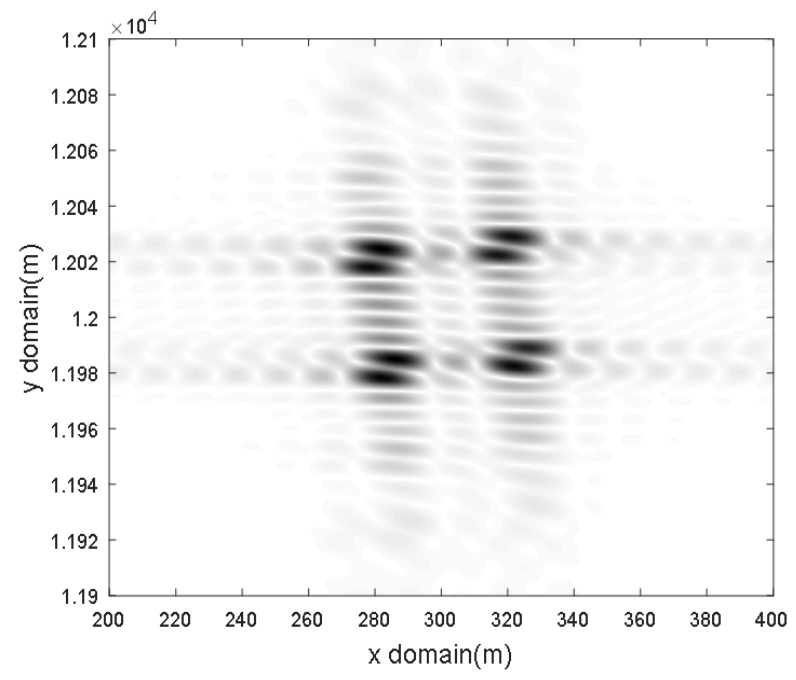

그림 4. $(M, N)=(1,20)$ 인 경우

Fig. 4. In case of $(M, N)=(1,20)$.

분의 스펙트럼 샘플 간 간격이 $\triangle_{g r i d}$ 이상이 되도록 수신 기 간의 거리를 크게 했다. 또한 수신기 5 개 중 2 개는 고도 가 0 이 아니고 $10 \mathrm{~m}$ 로 일부러 설정한 후 참고문헌 [6]에 제시된 고도 보정 알고리즘을 적용하였다. 그림 5(a) 및 그림 $5(\mathrm{~b})$ 는 송신기가 1,2 개일 때 얻어진 표적 영상 결과 이다. 식 (9)의 조건을 만족시키지 못해서 앨리어싱 현상 이 발생하는 것을 확인할 수 있었으며, 송신기 개수가 2 개로 늘어났을 때 앨리어싱 현상이 약간 완화되었다.

그림 6은 식 (8)을 만족하도록 송신기 4개를 배치하였 을 때 얻어진 이미징 결과이다. 공간 스펙트럼 평면에서 표적 성분의 샘플 간격 및 차지하는 범위가 $(M, N)$ 이 $(1,20)$ 일 때와 거의 유사하도록 송수신기 위치를 설정했 다. 이 경우, 해상도 및 앨리어싱 현상 측면에서 그림 4의 결과와 거의 유사하였다.

그림 7은 각 송신기들이 서로 직교하는 송신 펄스를 전송 하는 $\mathrm{MIMO}$ 레이다에 대한 시뮬레이션 결과로서 $(M, N)$ 이 $(4,5)$ 인 경우이다. 송신 펄스의 직교성은 chirp rate이 서로 다른 linear FM 신호를 사용해서 얻었다. 그림 6과 비교했을 때 표적 이미징 성능의 열화가 발생하는 것을 확인할 수 있다. 이는 송신 파형 간의 약간의 상호 상관도 (cross correlation)가 존재하여 발생한 결과라고 해석할 수 있으며, 이는 더욱 큰 직교성을 갖도록 파형을 적절히 설 


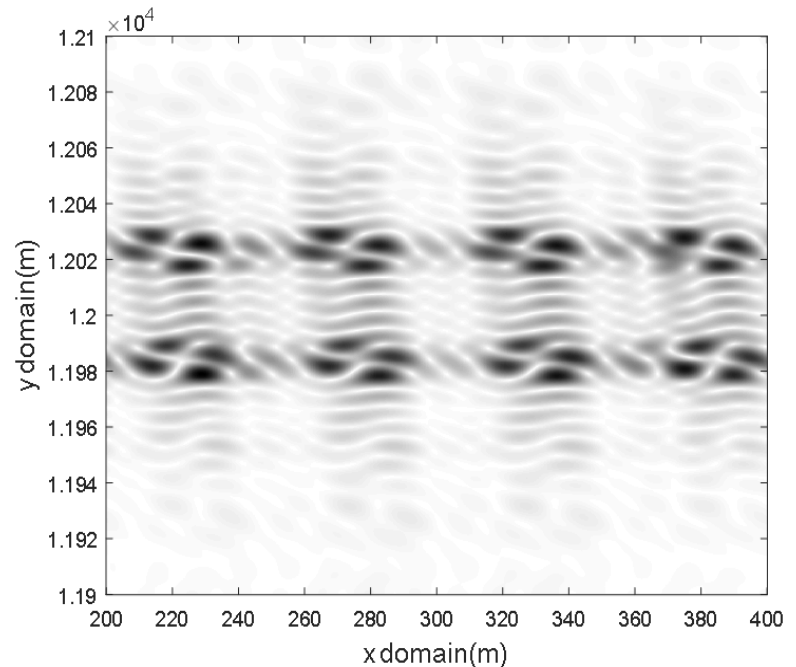

(a) $(M, N)=(1,5)$

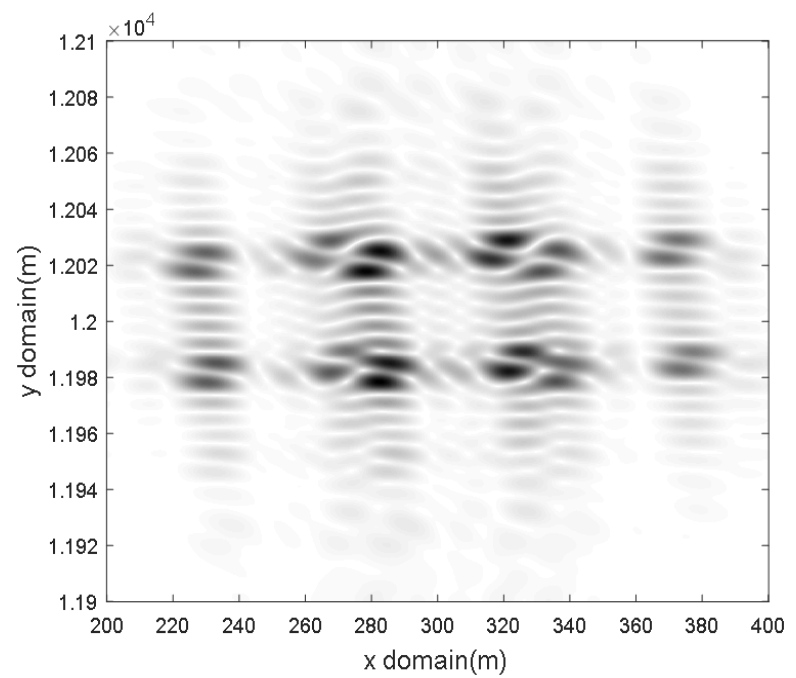

(b) $(M, N)=(2,5)$

그림 5. 수신기간 이격이 큰 경우

Fig. 5. In case of large distance between the receivers.

계함으로써 이러한 현상을 해결할 수 있다.

\section{IV. 결 론}

본 논문에서는 지상에 복수의 송수신기들이 배치된 $\mathrm{MIMO}$ 레이다 환경에서 polar processing 기법을 적용하여 이동 표적을 이미징할 수 있는 알고리즘을 제안하였다. 제시된 환경에서 표적 성분이 공간 스펙트럼 평면에서

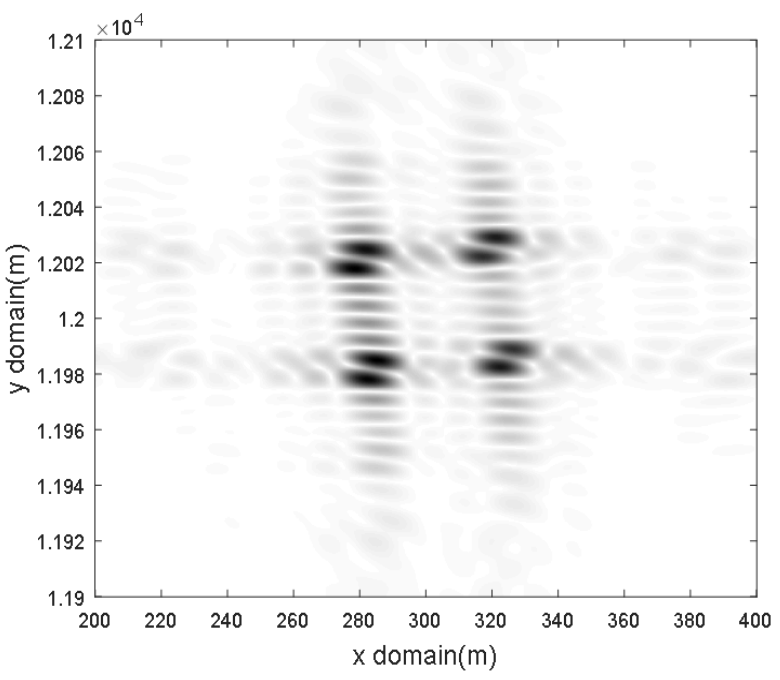

그림 6. $(M, N)=(4,5)$ 인 경우

Fig. 6. In case of $(M, N)=(4,5)$.

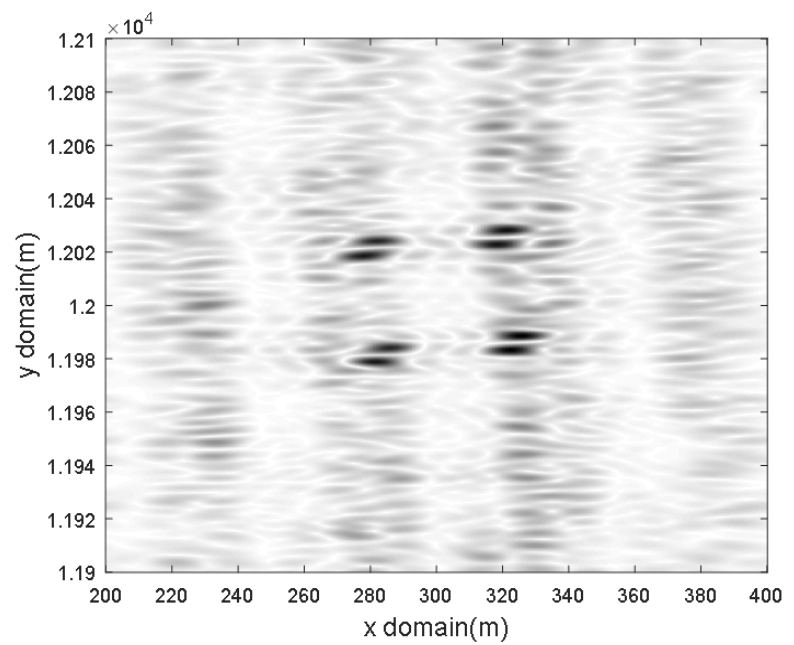

그림 7. $\mathrm{MIMO}$ 레이다 구조를 사용했을 경우

Fig. 7. Acquired image in situation of MIMO radar structure.

차지하는 영역을 조사했으며, 이에 근거해서 수신기가 멀 리 떨어진 경우에도 송신기들의 적절한 배치를 통해서 앨리어싱 현상이 완화되고, 해상도가 개선된 영상을 얻을 수 있음을 보였다. 제시된 시스템은 펄스 송신 방법에 따 라 MIMO 및 virtual MIMO 형태로 운용 가능하며, 각각의 경우에 대해서 구현 가능한 조건을 제시하였다. 또한 클 러터 성분이 많은 경우 제시된 시스템에 $\mathrm{DPCA}$ 기능을 
추가하면 클러터를 억제하면서 이동 표적 이미징이 가능 함을 보이고 시뮬레이션에 의해 검증하였다.

\section{References}

[1] H. Griffiths, "Passive bistatic radar," in Academic Press Library in Signal Processing: Communications and Radar Signal Processing, vol. 2, pp. 813-855, New York, NY, Academic, 2014.

[2] M. Martorella, "Introduction to inverse synthetic aperture radar," in Academic Press Library in Signal Processing: Communications and Radar Signal Processing, vol. 2, pp. 987-1042, New York, NY, Academic, 2014.

[3] P. Abiven, T. J. Lim, and J. Pisane, "FM passive bistatic radar imaging of airplanes in a real configuration," in

\section{최 상 현 [광운대학교/석사과정]}

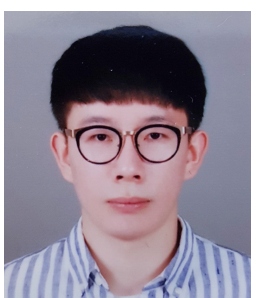

2011년 3월: 광운대학교 전자융합공학과 (공학사)

2017년 3월 현재: 광운대학교 전파공학과 석사과정

[주 관심분야] 무선통신 시스템, 레이다 신호처리
2014 International Radar Conference, Lille, Oct. 2014, pp. 1-6.

[4] D. Pastina, M. Bucciarelli, and P. Lombardo, "Multistatic and MIMO distributed ISAR for enhanced cross-range resolution of rotating targets," IEEE Transactions on Geoscience and Remote Sensing, vol. 48, no. 8, pp. 33003317, Aug. 2010.

[5] M. Martorella, F. Berizzi, and B. Haywood, "A contrast maximization based technique for 2D ISAR autofocusing," in IEE Proceedings-Radar, Sonar and Navigation, vol. 152, no. 4, pp. 253-262, Aug. 2005.

[6] 최상현, 양동혁, 송지민, 양훈기, "배열 구조 바이스태 틱 지대공 레이다의 이미징 기법," 한국전자파학회논 문지, 29(8), pp. 599-607, 2018년 8월.

\section{양 훈 기 [광운대학교/교수]}

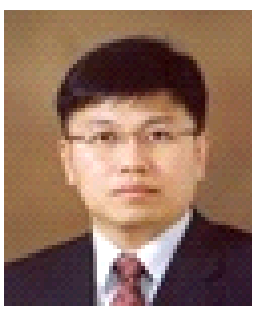

1985년 2월: 연세대학교 전자공학과 (공학 사) 1987년 5월: 미국 SUNY at Buffalo University 전기컴퓨터공학과 (공학석사) 1992년 4월: 미국 SUNY at Buffalo University 전기컴퓨터공학과 (공학박사) 1993년 3월 현재: 광운대학교 전파공학과 교수

[주 관심분야] 무선통신 시스템, UWB, RFID, 스펙트럼 공학, 레이다 신호처리 